\title{
Ovarian Pregnancy following Intracytoplasmic Sperm Injection and Embryo Transfer: A Case Report
}

\author{
Amar Ramachandran, ${ }^{1}$ Swati Sharma, ${ }^{2}$ Kumar Pratap, ${ }^{1}$ Bhakta Rajesh, ${ }^{1}$ Vasudeva Akhila, ${ }^{1}$ \\ Akhila Ramayapally, ${ }^{1}$ and Manna Valiathan ${ }^{2}$ \\ ${ }^{1}$ Department of OBG, Kasturba Medical College, Manipal 576104, India \\ ${ }^{2}$ Department of Pathology, Kasturba Medical College, Manipal 576104, India
}

Correspondence should be addressed to Amar Ramachandran, docramar@gmail.com

Received 31 March 2012; Accepted 15 May 2012

Academic Editors: B. A. Gbolade, E. F. C. Murta, D. Ogunyemi, and B. Piura

Copyright (C) 2012 Amar Ramachandran et al. This is an open access article distributed under the Creative Commons Attribution License, which permits unrestricted use, distribution, and reproduction in any medium, provided the original work is properly cited.

Ovarian pregnancy is a rare form of ectopic pregnancy following ICSI-ET, and the diagnosis depends on the physicians suspicion and experience. Preservation of ovarian tissue during surgery is of utmost importance to preserve fertility. We present a case of ovarian pregnancy who had a successful treatment preserving the ovary.

\section{Introduction}

The incidence of an ectopic pregnancy varies in a range between $0.3 \%$ and $1.4 \%$ of all pregnancies [1]. An increased incidence of ectopic pregnancies up to $5-6 \%$ after in vitro fertilization (IVF) and embryo-transfer (ET) is a well-known phenomenon. However, primary ovarian pregnancy is a rare phenomenon following natural conception or IVF-ET. The incidence of primary ovarian pregnancy is $3.3 \%$ of all ectopic pregnancies [2], and the incidence reported following IVFET is $0.27 \%$ per clinical pregnancy [3]. We report a case of primary ovarian pregnancy following ICSI for primary infertility treatment. The case presented here is interesting in terms of both the rarity of this entity and the successful therapy preserving the ovary.

\section{Case Report}

She was 33 years, and married for 4.5 years. She underwent ICSI for male factor infertility. Serum $\beta$-hcg on the fourteenth day of embryo transfer (ET) was $39 \mathrm{mIU} / \mathrm{mL}$. She had spotting per vagina 5 days later (19th day of ET), and the serum $\beta$-hcg was $118.1 \mathrm{mIU} / \mathrm{mL}$. The vaginal sonography did not reveal an intrauterine or extrauterine gestational sac, and she was followed up. On the 30th day of ET ( 6 weeks period of gestation), she presented to the hospital with complains of pain abdomen for one day and gradual distension of the abdomen. Clinically, she was pale, but the vital signs were stable. Vaginal sonography showed uterine cavity empty, right adnexa had a hypoechoic area of $2.5 \mathrm{~cm} \times 2.1 \mathrm{~cm}$, and the left adnexa was normal. There was significant fluid in the pouch of Douglas. Serum $\beta$-hcg was not repeated at that time. Emergency laparotomy was performed with the diagnosis of ectopic pregnancy. $300 \mathrm{~mL}$ of blood and $150 \mathrm{gm}$ of clot were seen in the peritoneal cavity. Right ovary was found ruptured and bleeding actively, and hence right side partial ovariectomy was performed and sutured. Both the fallopian tubes and left ovary were normal. The pathologic examination confirmed the clinical diagnosis (Figures 1 and 2). She had ICSI twice later and oocytes were retrieved from right ovary too. She conceived in the second attempt and delivered a male child.

\section{Discussion}

Primary ovarian pregnancy is an uncommon form of ectopic pregnancy. Marcus and Brinsden reported an incidence of $6 \%$ following IVF-ET ( 8 primary ovarian pregnancies following 135 ectopic pregnancies after IVF-ET) [4]. But the incidence following natural conception is much lower, 


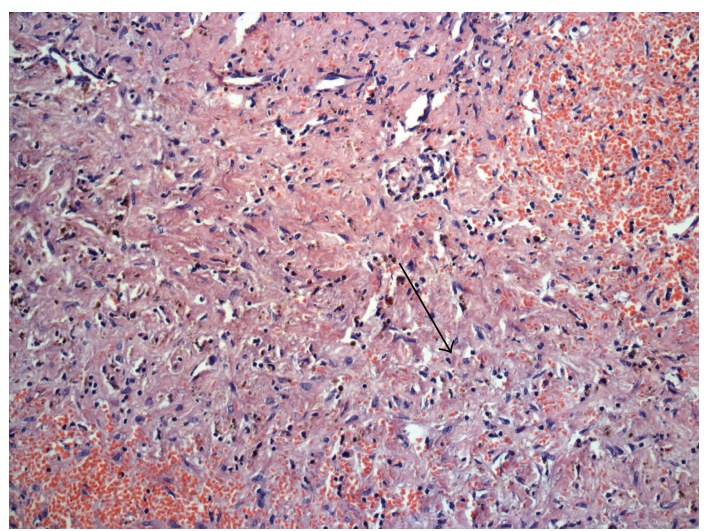

FIgURe 1: Ovarian stroma H\&E $\times 100$.

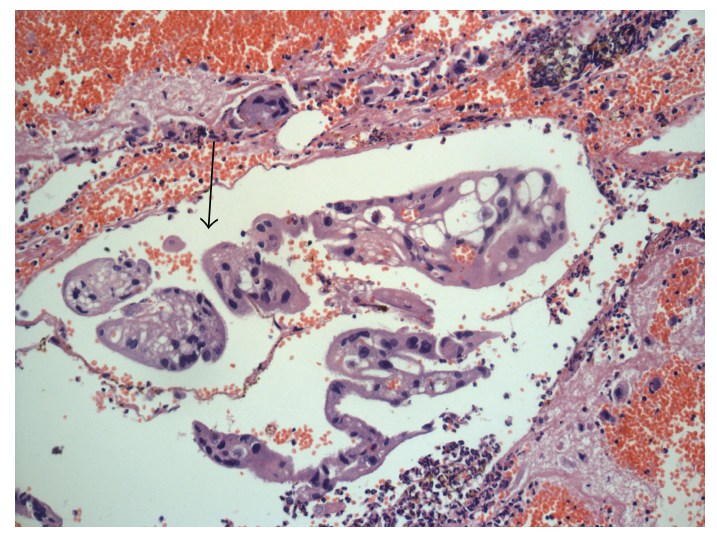

Figure 2: Trophoblast in hemorrhagic stroma. H\&E $\times 100$.

ranging from $1 / 16,000$ to $1 / 1,500$ deliveries accounting for $3.3 \%$ of all ectopic pregnancies.

The four Spiegelberg's criteria for ovarian ectopic gestation are: (1) fallopian tubes including fimbria must be intact and separate from the ovary; (2) the pregnancy must occupy the normal position of the ovary; (3) the ovary must be attached to the uterus through the utero-ovarian ligament; and (4) there must be ovarian tissue attached to the pregnancy in the specimen [5].

Diagnosis of primary ovarian pregnancy is very difficult because of the rarity and the asymptomatic nature before rupture. Although the combination of serum $\beta$-hcg and vaginal sonography increases the diagnostic accuracy of ectopic pregnancy, the diagnosis of primary ovarian pregnancy depends on the physicians suspicion and experience. As a rule, if the serum $\beta$-hcg level is $>1000 \mathrm{mIU} / \mathrm{mL}$ without an intrauterine gestational sac by vaginal sonography, patient is regarded to have ectopic pregnancy.

Fertilisation of the ovum inside the ovary or implantation of the fertilised ovum in the ovary seems to be most responsible causes in the etiology and pathogenesis of ovarian ectopic pregnancy. In the case we described, the exact mechanism of ovarian pregnancy after ICSI was unclear since there were no predisposing factors for ectopic pregnancy except that four embryos have been transferred in our case.
One of the most likely probabilities is reverse migration of one of these embryos toward the fallopian tube and implantation in the ovary [6]. This unusual event could be a result of the volume and pressure of culture medium injected during embryo transfer. Another contributory factor in the pathogenesis might be head tilted down position given to the patient following ET. Knutzen introduced the reverse migration concept and demonstrated the fate of embryos "in utero" by observing that radiopaque dye could enter the fallopian tubes in $38.2 \%$ of the patients easily after a mock ET [7]. In our patient, a tilted position was given following ET and $10-15 \mu \mathrm{L}$ of the media was used and the transfer was done under ultrasound guidance. Difficult ET may be another possible factor due to resulting in additional stimulation of junctional zone contractions which increases the risk of ectopic pregnancy. Lesny et al. showed that a difficult ET stimulates junctional zone contractions and that strong endometrial waves in the fundal area of uterus could move mock embryos into the fallopian tubes. They also noted that manipulation with tissue forceps, for the purpose of facilitating ET, could affect uterine contractility [8] but such events were not encountered at the time of ET in this patient. Reverse migration of an embryo also could be due to high estrogen levels after ovarian stimulation [9]. In our case, serum estradiol concentration was $4300 \mathrm{pg} / \mathrm{mL}$ on the day of HCG injection.

The therapy of early ovarian pregnancy is surgical in the first place, and in the event that the patient desires a future pregnancy, the conservation of ovarian tissue is the clinical goal of the treatment. In our case, we could preserve the ovaries and she could conceive later and deliver.

\section{References}

[1] S. Kissler, I. Wiegratz, J. Kohl, A. Rody, R. Gaetje, and M. Kaufmann, "Repeated ectopic pregnancy after ICSI therapy and embryo transfer-a case report and literature review," Journal fur Reproduktionsmedizin und Endokrinologie, vol. 3, no. 6, pp. 387-389, 2006.

[2] F. G. Oliveira, V. Abdelmassih, A. L. E. Costa, J. P. Balmaceda, S. Abdelmassih, and R. Abdelmassih, "Rare association of ovarian implantation site for patients with heterotopic and with primary ectopic pregnancies after ICSI and blastocyst transfer," Human Reproduction, vol. 16, no. 10, pp. 2227-2229, 2000.

[3] M. Han, J. Kim, H. Kim, G. Je, and T. Hwang, "Bilateral ovarian pregnancy after in vitro fertilization and embryo transfer in a patient with tubal factor infertility," Journal of Assisted Reproduction and Genetics, vol. 21, no. 5, pp. 181-183, 2004.

[4] S. F. Marcus and P. R. Brinsden, "Primary ovarian pregnancy after in vitro fertilization and embryo transfer: report of seven cases," Fertility and Sterility, vol. 60, no. 1, pp. 167-169, 1993.

[5] O. Spiegelberg, "Zur casuistik den ovarial-schwangenschaft," Archiv für Gynäkologie, vol. 13, p. 73, 1878.

[6] C. S. Pope, E. K. D. Cook, M. Arny, A. Novak, and D. R. Grow, "Influence of embryo transfer depth on in vitro fertilization and embryo transfer outcomes," Fertility and Sterility, vol. 81, no. 1, pp. 51-58, 2004.

[7] V. Knutzen, C. J. Stratton, G. Sher, P. I. McNamee,T. T. Huang, and C. Soto-Albors, "Mock embryo transfer in early luteal 
phase, the cycle before in vitro fertilization and embryo transfer: a descriptive study," Fertility and Sterility, vol. 57, no. 1, pp. 156-162, 1992.

[8] P. Lesny, S. R. Killick, J. Robinson, G. Raven, and S. D. Maguiness, "Junctional zone contractions and embryo transfer: is it safe to use a tenaculum?" Human Reproduction, vol. 14, no. 9, pp. 2367-2370, 1999.

[9] C. S. Atabekoglu, B. Berker, and I. Dunder, "Ovarian ectopic pregnancy after intracytoplasmic sperm injection," European Journal of Obstetrics Gynecology and Reproductive Biology, vol. 112, no. 1, pp. 104-106, 2004. 


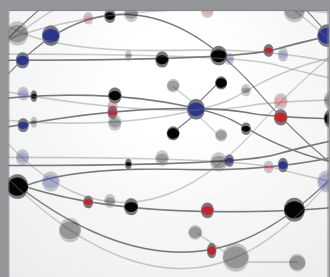

The Scientific World Journal
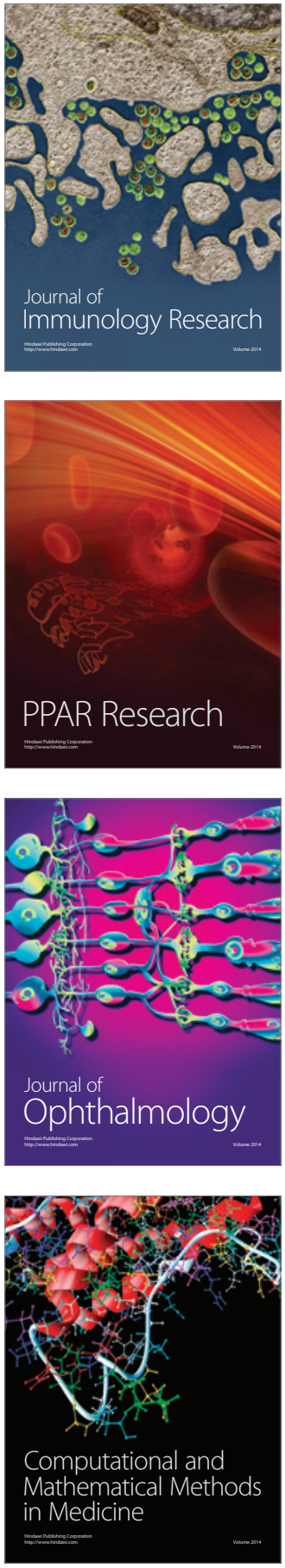

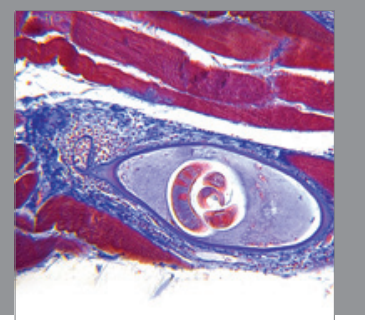

Gastroenterology

Research and Practice
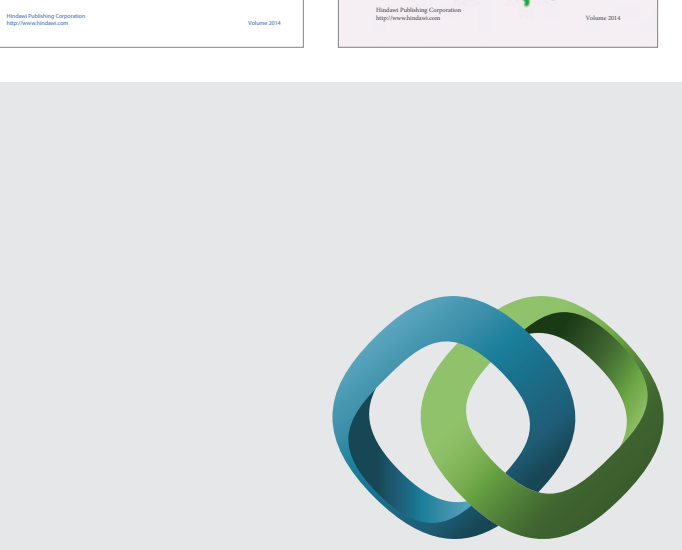

\section{Hindawi}

Submit your manuscripts at

http://www.hindawi.com
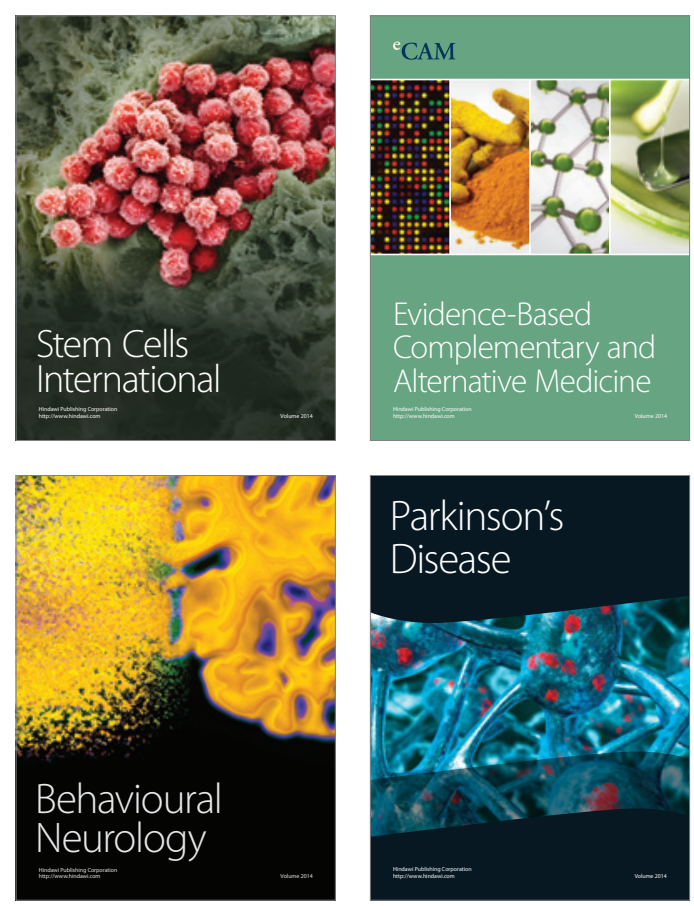

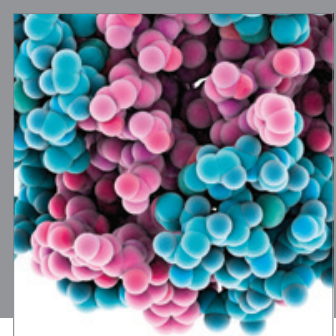

Journal of
Diabetes Research

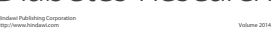

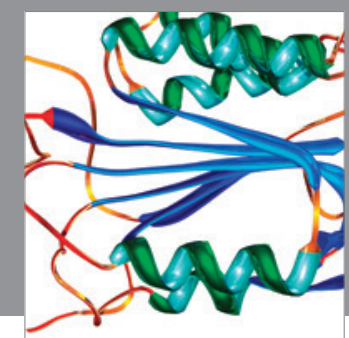

Disease Markers
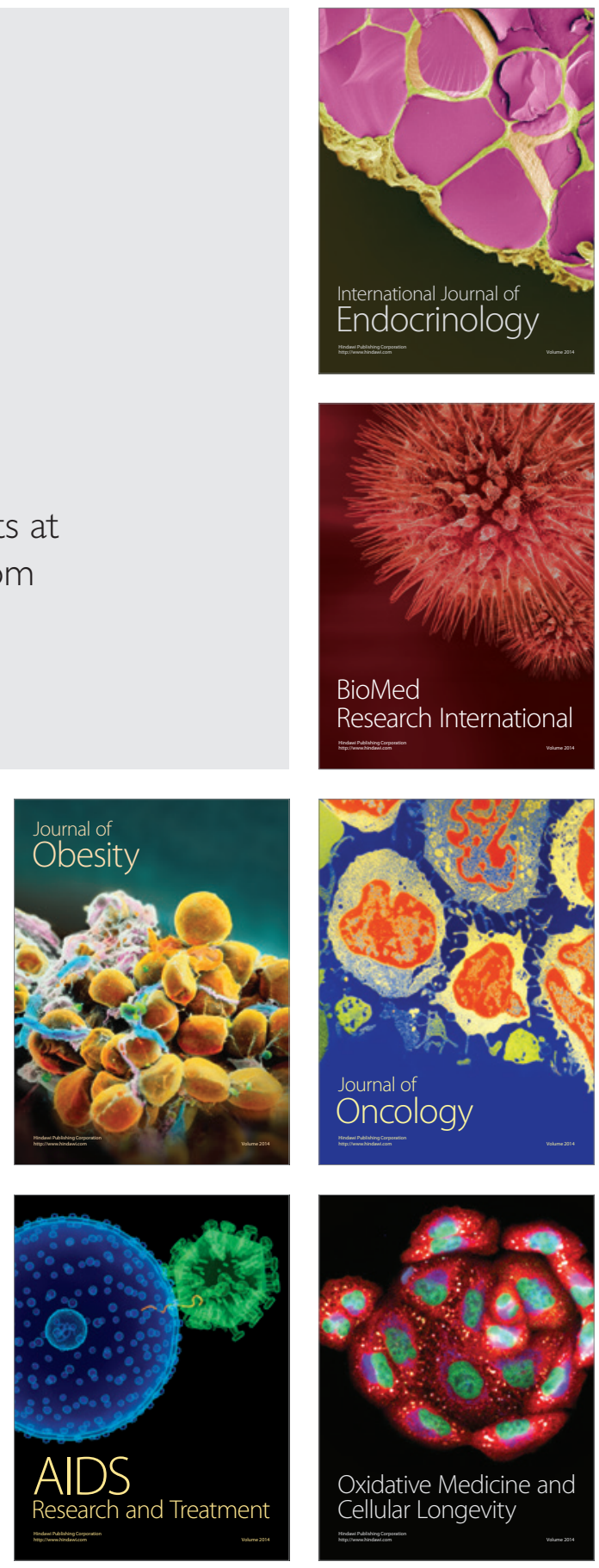